J. Lake Sci.(湖泊科学), 2022, 34(2): 496-505

DOI 10. 18307/2022. 0211

(c) 2022 by Journal of Lake Sciences

\title{
白洋淀湿地表层土壤主要环境元素分布特征及来源
}

\author{
刘雪松**, 王雨山, 王旭清, 尹德超 \\ (中国地质调查局水文地质环境地质调查中心 , 保定 071051)
}

\begin{abstract}
摘 要: 白洋淀是雄安新区生态共同体的重要组成部分, 在 “白洋淀生态环境治理和保护规划” 中, 淀区内纯水村和耕地 将被淹没, 而上述陆地的土壤环境元素分布特征及来源仍缺乏系统调查和分析. 本文以淀区内现有 $0 \sim 20 \mathrm{~cm}$ 土壤为研究 对象, 以环境元素 $\mathrm{As} 、 \mathrm{Hg} 、 \mathrm{Cd} 、 \mathrm{Cr} 、 \mathrm{~Pb} 、 \mathrm{Ni} 、 \mathrm{Cu} 、 \mathrm{Zn} 、 \mathrm{~N} 、 \mathrm{P}$ 和土壤类型、质地为研究要素, 以统计描述、方差分析、相关分析和因 子分析为研究手段对淀区内土壤主要环境元素分布特征和来源进行刻画和分析. 结果表明: 淀区主要环境元素在不同土 地类型的差异性分布是大气沉降和人类工农业活动综合作用的结果. 除元素 P 外,其余环境元素的淀区背景值均高于区 域背景值, 呈富集趋势. 大部分元素趋向于在农用地富集, 在水田的富集最为突出, $\mathrm{Hg}$ 元素则更易在村镇用地富集. 淀区 内土壤主要环境元素来源分 3 种类型: 大气沉降型,代表元素为 $\mathrm{Ni} 、 \mathrm{Cr} 、 \mathrm{As} 、 \mathrm{~Pb} 、 \mathrm{Cu}$ 和 $\mathrm{Cd}$, 主要来自区域燃煤烟气的沉降 输人; 农业输人型, 代表元素为 $\mathrm{P} 、 \mathrm{~N} 、 \mathrm{Hg} 、 \mathrm{Cd} 、 \mathrm{~Pb}$, 主要来自本地农业施肥和人类生活垃圾输人; 工业叠加型, 代表元素为 $\mathrm{Zn} 、 \mathrm{Cu} 、 \mathrm{Cd} 、 \mathrm{~Pb}$, 主要来自大气沉降和淀区临近的小冶炼的排放叠加,其中 $\mathrm{Pb} 、 \mathrm{Cd} 、 \mathrm{Cu}$ 为综合输人方式.
\end{abstract}

关键词: 白洋淀; 土地类型; 环境元素;分布特征; 来源分析

\section{Distribution characteristics and source of the main environmental elements in the surface soil of Lake Baiyangdian wetlands*}

Liu Xuesong ** Wang Yushan, Wang Xuqing \& Yin Dechao

( Hydrogeology and Environmental Geology Survey Center of CGS, Baoding 071051, P.R.China)

\begin{abstract}
Lake Baiyangdian is an important part of Xiongan's ecological community. In the "Lake Baiyangdian Ecological Environment Management and Protection Plan”, water villages and farmland in Lake Baiyangdian will be submerged. The survey and analysis of soil environmental elements are still rare on the lands in Lake Baiyangdian. This paper takes the 0-20 cm soil of Lake Baiyangdian's lands to examine the pollution patterns of $\mathrm{As}, \mathrm{Hg}, \mathrm{Cd}, \mathrm{Cr}, \mathrm{Pb}, \mathrm{Ni}, \mathrm{Cu}, \mathrm{Zn}, \mathrm{N}$ and $\mathrm{P}$ elements using statistical description, correlation analysis, variance analysis and factor analysis. The results show that the significant differences in the distribution of main environmental elements on different types of land soil in Lake Baiyangdian are the result of the combined effects of atmospheric deposition with human industrial and agricultural activities. Besides the $\mathrm{P}$, all the other environmental elements' background values are higher than those in around areas. It tends to enrichment. Most of the elements are enriched in agricultural lands, especially in paddy fields, but the $\mathrm{Hg}$ element is more easily enriched in village lands. Environmental elements in the lands of Lake Baiyangdian come from three ways: $\mathrm{Ni}, \mathrm{Cr}, \mathrm{As}, \mathrm{Pb}, \mathrm{Cu}, \mathrm{Cd}$ are mainly from the atmosphere and coal burning, P, N, Hg, Cd, $\mathrm{Pb}$ are mainly from fertilizer and activities of human, $\mathrm{Zn}, \mathrm{Cu}, \mathrm{Cd}, \mathrm{Pb}$ are mainly from the small melting workshop.
\end{abstract}

Keywords: Lake Baiyangdian; land types; environmental elements; distribution characteristics; source analysis

内陆湖泊是地球表层系统各圈层相互作用的联结点, 是陆地水圈的重要组成部分, 与生物圈、大气圈、 岩石圈等关系密切, 具有调节区域气候、记录区域环境变化、维持区域生态系统平衡和繁衍生物多样性的特 殊功能. 近年来受水资源过度利用、水环境恶化等因素的影响, 导致我国许多内陆湖泊出现富营养化、水体 污染、湖泊萎缩、生物多样性减少等不同类型的环境问题 ${ }^{[1-2]}$. 白洋淀是我国华北平原为数极少且最大的淡

* 2021-05-21 收稿; 2021-07-25 收修改稿.

中国地质调查局白洋淀地区生态地质调查项目( DD20190300) 资助.

** 通信作者; E-mail: 26426556@ qq.com. 
水湖泊,享有 “华北之肾”、“华北明珠” 等美誉 ${ }^{[3-4]}$, 具有缓洪滞沥、蓄水灌溉、调节局部地区气候、改善生态 环境、补充地下水、保护生物多样性等多种生态功能 ${ }^{[5-6]}$. 近年来, 在人类活动和气候变化的综合作用下,白 洋淀生态环境条件发生很大变化, 呈现出人淀水量减少, 湿地萎缩、连通性变差、环境元素富集、生物多样性 减少等诸多生态危机 ${ }^{[7-12]}$. 雄安新区成立后, 白洋淀成为新区“淀水林田草生命共同体” 的重要组成部分. 逐 步恢复淀区面积,建设白洋淀国家公园,有效治理农村面源污染, 恢复“华北之肾”功能, 成为白洋淀远景规 划来的发展定位 ${ }^{[13]}$.

以往白洋淀淀内的环境元素研究与分析, 侧重于重金属和氮、磷元素, 其赋存介质主要集中在水体和底 泥, 研究表明白洋淀水体整体处于富营养状态, 底泥中的砷、镉处于较重一重污染状态 ${ }^{[14-15]}$. 淀区外 (千里堤 范围外) 耕地区开展了 $1: 5$ 万的土地质量地球化学调查, 但对于淀区内星罗棋布的台地、纯水村及少量耕地 等土壤环境元素的分布特征尚未未开展过调查工作,对其来源更是缺乏系统的研究. “白洋淀生态环境治理 和保护规划 (2018-2035 年)”要逐步恢复湿地, 现有的纯水村、耕地和其他类型的陆地都将被淹没,淹没后 土壤重金属元素和氮磷等营养物质元素的释放将对水体污染和富营养化产生一定的影响. 因此开展淀区内 现有非淹没区土壤主要环境元素的分布特征和物源分析可为淀区陆地的淹没风险评价提供科学依据.

本文以白洋淀淀内现有非淹没的 $0 \sim 20 \mathrm{~cm}$ 表层土壤为工作对象, 以淀中土地利用类型为主要分类准 则, 以 $\mathrm{As} 、 \mathrm{Hg} 、 \mathrm{Cd} 、 \mathrm{Cr} 、 \mathrm{~Pb} 、 \mathrm{Ni} 、 \mathrm{Cu} 、 \mathrm{Zn}$ 和 $\mathrm{N} 、 \mathrm{P}$ 为分配特征和来源为研究内容, 以统计分析、方差分析、相关分析 和因子分析为主要分析手段,对淀区土壤主要环境元素物源归属进行分析和探讨, 以期为白洋淀淀区水面 恢复时的环境整治实施提供数据支撑.

\section{1 材料与方法}

\section{1 研究区概况}

白洋淀位于雄安新区南部, 是大清河流域中部的天然湖泊, 是华北平原上为数极少的淀泊之一, 也是雄 安新区发展的重要生态水体. 淀区由白洋淀、藻苲淀、马棚淀、烧车淀等 143 个大小不等的淀泊组成, 总面积 约 $366 \mathrm{~km}^{2}$. 淀区内河淀相连、沟㛑纵横, 围埝、台田、村庄交错分布, 景观格局较为破碎 ${ }^{[16]}$. 淀区主要由水 体、湿地植被、水田、旱田和居民建设用地 5 种类型构成. 其中水体 $144.77 \mathrm{~km}^{2}$, 湿地植被 $80.22 \mathrm{~km}^{2}$, 水田 $11.22 \mathrm{~km}^{2}$, 旱地 $76.56 \mathrm{~km}^{2}$, 建设用地 $28.83 \mathrm{~km}^{2[17]}$.

\section{2 样品采集与分析}

根据淀区内部的景观格局现状, 以千里堤范围内常年出露, 不被水淹的 $0 \sim 20 \mathrm{~cm}$ 土壤为样品采集对象, 样品分布的土地利用类型主要为居民建设用地、旱地、水田和林草荒地. 样品采集分 2019 年和 2020 年两次 采集完毕. 样品采集以典型性和代表性为主要原则, 面积超过 $66666 \mathrm{~m}^{2}$ 的水田、旱地由于均质性较好, 采用 网格化布样方法, 对于碎块化的居民建设用地和林草荒地, 根据地块形状和地物分布采用判断布样法, 以体 现样品的代表性原则. 合计化学分析样品为 420 个, 样品平均分布密度为 4 个 $/ \mathrm{km}^{2}$ (图 1); 物理岩性分析样 品根据不同土地利用类型, 按照 $10 \%$ 比例进行篮选,合计 42 个.

化学分析样品经干燥、去杂质和过篮 (孔径为 $2 \mathrm{~mm}$ ) 后, 送河北省地质实验测试中心进行分析, 分析方 法依据 LY/T 1228-2015 和 DZ/T 0130-2006, 土壤样品测定的 As、Cd、Cr、Cu、 Hg、Ni、Pb、Zn 在样品经混酸 $\left(\mathrm{HNO}_{3}-\mathrm{HF}\right)$ 于 $140^{\circ} \mathrm{C}$ 电热板上持续加热消解后, 采用电感耦合等离子发射光谱法测定. 土壤样品的总氮 (TN) 含量采用凯氏氮蒸馏一酸碱滴定法测定, 土样中的总磷 (TP) 含量采用高氯酸一硫酸法酸化分解, 比色 法测定.

土壤岩性样品送中国地质调查局水文地质环境地质调查中心土工实验室进行分析, 粗粒采用笁析法, 细粒采用密度计法.

\section{3 数据处理}

本文采用 SPSS 19 软件对土壤样品测试结果进行统计分析, 以统计描述、方差分析、相关分析和因子分 析为主要数据分析手段, 确定陆面土壤环境元素含量之间的关系; 采用 ArcGIS 软件, 反距离权重插值法对其 分布特征进行空间分析; 综上数据处理手段,综合分析其分布特征和物质来源. 


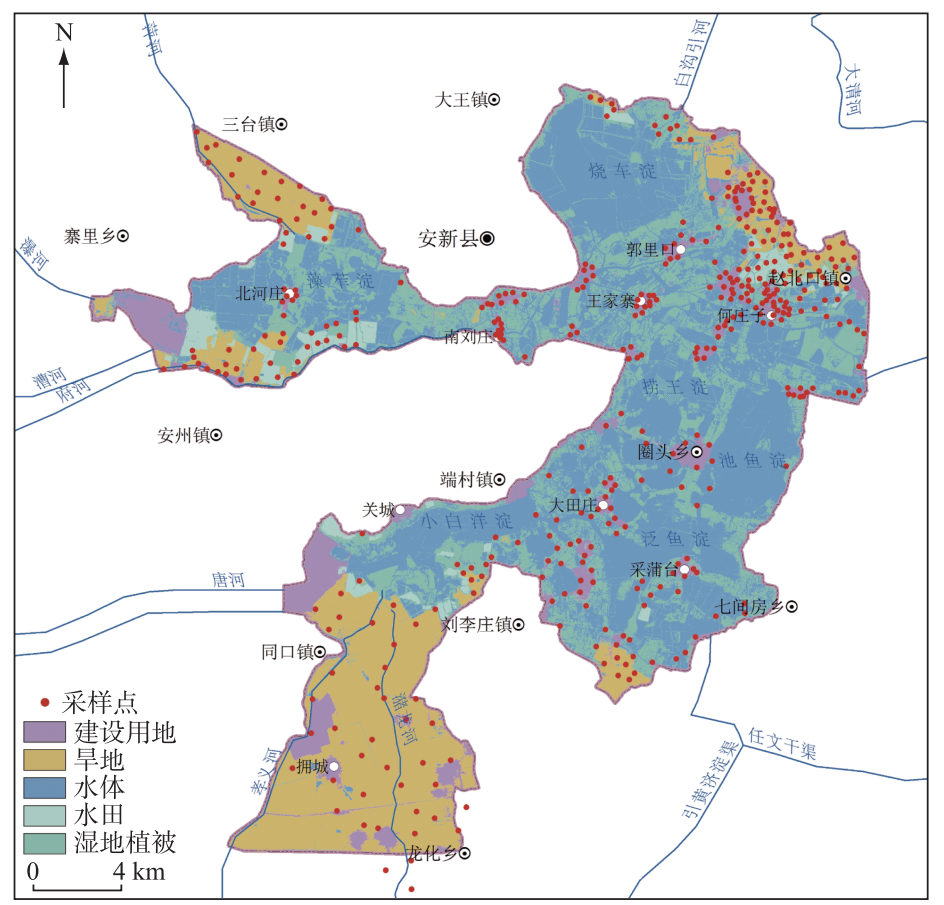

图 1 白洋淀淀区陆面样品分布

Fig. 1 Distribution of sampling sites on Lake Baiyangdian lands

\section{2 结果与分析}

\section{1 白洋淀主要土壤环境元素含量分布特征}

淀区土壤主要环境元素含量的统计特征如表 1 所示. 为了更准确地对比淀区土壤环境元素和临近区域 土壤元素含量分布的差异性, 区域背景值采用海河平原北部地区之冲积一冲湖积平原土壤地球化学基准值 统计参数 ${ }^{[18]}$, 而非整个河北平原的背景值. 为使淀区背景值和区域背景值相对应, 淀区背景值采用全部数 据剔除 2 倍标准差后的均值. 除元素 P 外,其余元素淀区背景值均高于区域背景值 (表 1), 说明淀区内土壤 环境元素, 受人类活动影响整体上呈现出富集的态势. 以 (淀区背景一区域背景)/淀区背景, 作为淀区元素 背景值的变化率对环境元素变化情况进行分组, 其中 As、Zn、P、Cr 的变化率均小于 $10 \%$, 与区域背景值无明 显差异; $\mathrm{N} 、 \mathrm{~Pb} 、 \mathrm{Cd} 、 \mathrm{Ni}$ 变化率在 13\% 17\% 之间, 稍高于区域背景值; $\mathrm{Hg} 、 \mathrm{Cu}$ 变化率在 $23 \% \sim 36 \%$, 显著高于 区域背景值. 说明人类影响方式和程度的差异, 导致淀区土壤环境元素在富集程度上呈现出分化的趋势. 从 变异系数 $C_{\mathrm{v}}$ 来看 ${ }^{[19]}$, 大部分元素变异系数在 $0.20 \sim 0.53$ 之间, 属于中等变异水平; $\mathrm{Hg}$ 元素变异系数超过 1.0 , 属于强变异水平, 而 $\mathrm{Hg}$ 也是显著高于区域背景值的元素.

与我国新修订的《农用地土壤污染风险管控标准》(GB 15618- 2018) 和《建设用地土壤污染风险管控 标准》( GB 36600-2018) 相比, Cd、 $\mathrm{Hg} 、 \mathrm{As} 、 \mathrm{~Pb} 、 \mathrm{Cr}$ 均低于土壤污染管制值, 仅有 $0.2 \%$ 的样品中 $\mathrm{As}$ 和 $0.7 \%$ 的 样品中 $\mathrm{Cu}$ 超土壤污染篮选值.

\section{2 白洋淀土壤主要环境元素空间分布特征}

淀区土壤主要环境元素分布特征如图 2 所示, 重金属元素 (Hg 除外)整体表现出相似的空间分布特征, 即淀区核心 (王家寨、圈头乡等淀中村) 区域元素含量表现为低值区, 淀区周边区域 (农用地) 元素含量相对 较高, 尤其在淀区李庄镇区域更为突出; 元素含量呈现出点状和片状结合分布的特征; 营养元素 N、P 分布, 在非农用地区域较为均匀, 在农用地中, 存在一定差异, $\mathrm{P}$ 元素比 $\mathrm{N}$ 元素含量较为丰富. 从具体分布特征上 看, $\mathrm{Ni} 、 \mathrm{Cr}$ 在整个淀内土壤中分布特征高度相似; $\mathrm{As} 、 \mathrm{Cd} 、 \mathrm{Ni} 、 \mathrm{Cr}$ 在整个淀内土壤中分布特征中高度相似; $\mathrm{As}$ 、 
$\mathrm{Pb}$ 在淀区南部农田中分布特征高度相似, $\mathrm{Cu} 、 \mathrm{Zn}$ 在淀区中部淀中村和东部农田和村镇混合带分布特征中高 度相似. 重金属元素 $\mathrm{Hg}$ 高值区仅分布在淀中和淀边 5 个村落,其余多为低值区.

整个淀区土壤 $\mathrm{pH}$ 低值区多分布在淀区核心区的淀中村和淀中高台地区域,在距离淀区水体较远的南 部农田区域, $\mathrm{pH}$ 呈现升高的趋势.

表 1 淀区土壤主要环境元素统计特征

Tab.1 Descriptive characteristics of main environmental element's contents in the soil

\begin{tabular}{ccccccccc}
\hline 元素 & 均值士标准差 & 淀区背景值 区域背景值 & $\begin{array}{c}\text { 土壤 } \\
\text { 篮选值 }\end{array}$ & 最小值 & 最大值 & $C_{\mathrm{v}}$ & 观测数 \\
\hline $\mathrm{As}$ & $10.92 \pm 2.85$ & 10.90 & 10.80 & $20^{*} / 25$ & 4.44 & 28.60 & 0.26 & 420 \\
$\mathrm{Hg}$ & $41.21 \pm 47.78$ & 35.66 & 28.27 & $1000^{*} / 3400$ & 9.75 & 567.50 & 1.16 & 420 \\
$\mathrm{Cr}$ & $72.33 \pm 11.64$ & 72.00 & 66.33 & $350^{*} / 250$ & 37.70 & 118.00 & 0.16 & 420 \\
$\mathrm{Cd}$ & $0.20 \pm 0.07$ & 0.19 & 0.16 & $0.8^{*} / 0.6$ & 0.08 & 0.56 & 0.37 & 420 \\
$\mathrm{~Pb}$ & $25.14 \pm 5.70$ & 24.60 & 22.67 & $240^{*} / 170$ & 11.60 & 65.70 & 0.23 & 420 \\
$\mathrm{Ni}$ & $33.98 \pm 6.68$ & 33.80 & 28.92 & 190 & 15.30 & 59.30 & 0.20 & 420 \\
$\mathrm{Cu}$ & $32.48 \pm 15.55$ & 30.80 & 22.67 & $200^{\#} / 100$ & 8.19 & 204.50 & 0.48 & 420 \\
$\mathrm{Zn}$ & $89.84 \pm 75.06$ & 81.60 & 73.79 & 300 & 35.20 & 459 & 0.32 & 420 \\
$\mathrm{~N}$ & $1194.81 \pm 630.54$ & 1124.00 & 992.20 & & 170.00 & 3580.00 & 0.53 & 420 \\
$\mathrm{P}$ & $954.30 \pm 423.16$ & 898.00 & 971.17 & & 489.10 & 3746.30 & 0.44 & 420 \\
$\mathrm{pH}$ & $8.37 \pm 0.25$ & 8.40 & 8.52 & & 7.62 & 9.20 & 0.03 & 420 \\
\hline
\end{tabular}

$\mathrm{Hg}$ 元素的单位为 $\mu \mathrm{g} / \mathrm{kg}, \mathrm{pH}$ 无量纲, 其他元素单位均为 $\mathrm{mg} / \mathrm{kg}$. 土壤篮选值 $*$ 代表水田,\#代表果园, 无标号代表其他.

\section{3 不同土地利用类型中环境元素分布特征}

淀区内主要土地利用类型和样品分布如下: 建设用地 163 组、水田 36 组、旱地 123 组、林草荒地 98 组. 上述陆面类型的样本量均超过 30 , 属于大样本类型 ${ }^{[20]}$, 样本均值抽样分布近似服从正态分布, 然后对环境 元素在 4 种陆面类型中的总体方差进行齐性检验,结果如表 2 所示, $\mathrm{Hg} 、 \mathrm{Ni} 、 \mathrm{Cu} 、 \mathrm{As} 、 \mathrm{P} 、 \mathrm{~N}$ 的 $P$ 值均小于 0.05 , 说明通过方差齐性分析, 适用于方差分析; $\mathrm{Cd} 、 \mathrm{Cr} 、 \mathrm{~Pb} 、 \mathrm{Zn}$ 的 $P$ 值大于 0.05 , 不适用方差分析, 采用 Welch 检 验和 Brown-Forsythe 检验 ${ }^{[21]}$. 具体检验结果如表 3 所示, 除 $\mathrm{Hg}$ 外, 其余元素的 $P$ 值均小于 0.05 , 说明 $\mathrm{Hg}$ 以 外不同陆面类型环境元素的均值之间有显著差异. 进一步对不同土地利用类型的环境元素均值进行多重比 较 (方差齐时用 LSD 法, 方差非齐时用 Games-Howell 法), 探讨影响的差异, 结果如表 4 所示. 绝大部分重金 属元素均值在建设用地和农用地 (旱田和水田) 表现出显著性差异 ( $\mathrm{Zn}$ 在建设用地和旱地无显著差异) ; 绝 大部分重金属元素均值在建设用地和林草荒地无显著性差异 ( Ni 除外); 绝大部分重金属元素均值在林草 荒地和农用地表现出显著性差异 (As 在林草荒地和旱地无显著差异) ; 农用地中水田和旱地类型中, 除 $\mathrm{Cr}$ 、 $\mathrm{Pb} 、 \mathrm{Zn}$ 无显著差异外, 其余元素具有显著性差异. 营养元素 $\mathrm{P}$ 在建设用地和水田、林草荒地和水田间无显著 差异, 其他土地利用类型间均有显著差异; $\mathrm{N}$ 元素建设用地和林草荒地无显著差异外, 在其他土地利用类型 间都具有显著性差异. 综上, 大部分元素在建设用地和林草荒地 2 种土地利用类型无显著差异性, 在建设用 地与农用地、林草荒地域农用地间表现出显著差异性, 说明农业活动是造成环境元素在不同类型的陆面分 布的主要原因,农业耕作方式的不同,引起除 $\mathrm{Cr} 、 \mathrm{~Pb} 、 \mathrm{Zn}$ 以外环境元素的分布差异.

基于不同土地利用类型中土壤环境元素分布差异,进一步分析其在上述土地利用类型中分布的差异原 因. 由于不同元素间的量级相差较大, 为将元素在同一值域范围内进行比较, 对环境元素在不同土地利用类 型的均值取自然对数, 以陆面类型为横轴, 以均值自然对数为纵轴绘制环境元素分布折线图 (图 3 ). 由图中 可以看出, 重金属元素除 $\mathrm{Hg}$ 外, $\mathrm{Ni} 、 \mathrm{Cu} 、 \mathrm{Cr} 、 \mathrm{As} 、 \mathrm{~Pb} 、 \mathrm{Zn}$ 均表现出在农用地富集的趋势, 其中以水田富集最为 显著; 痕量元素 $\mathrm{Cd}$ 的含量取对数后为负值, 因此不在图中表示, 但其实际含量均值特征与除 $\mathrm{Hg}$ 以之外的其 他重金属相似. $\mathrm{Hg}$ 元素则表现为在建设用地最为富集, 其次为农用地, 在林草荒地富集程度最低. 与大多数 重金属相似,富营养元素 $\mathrm{N}$ 在水田富集最为显著; $\mathrm{P}$ 元素则在旱地富集最为显著. 

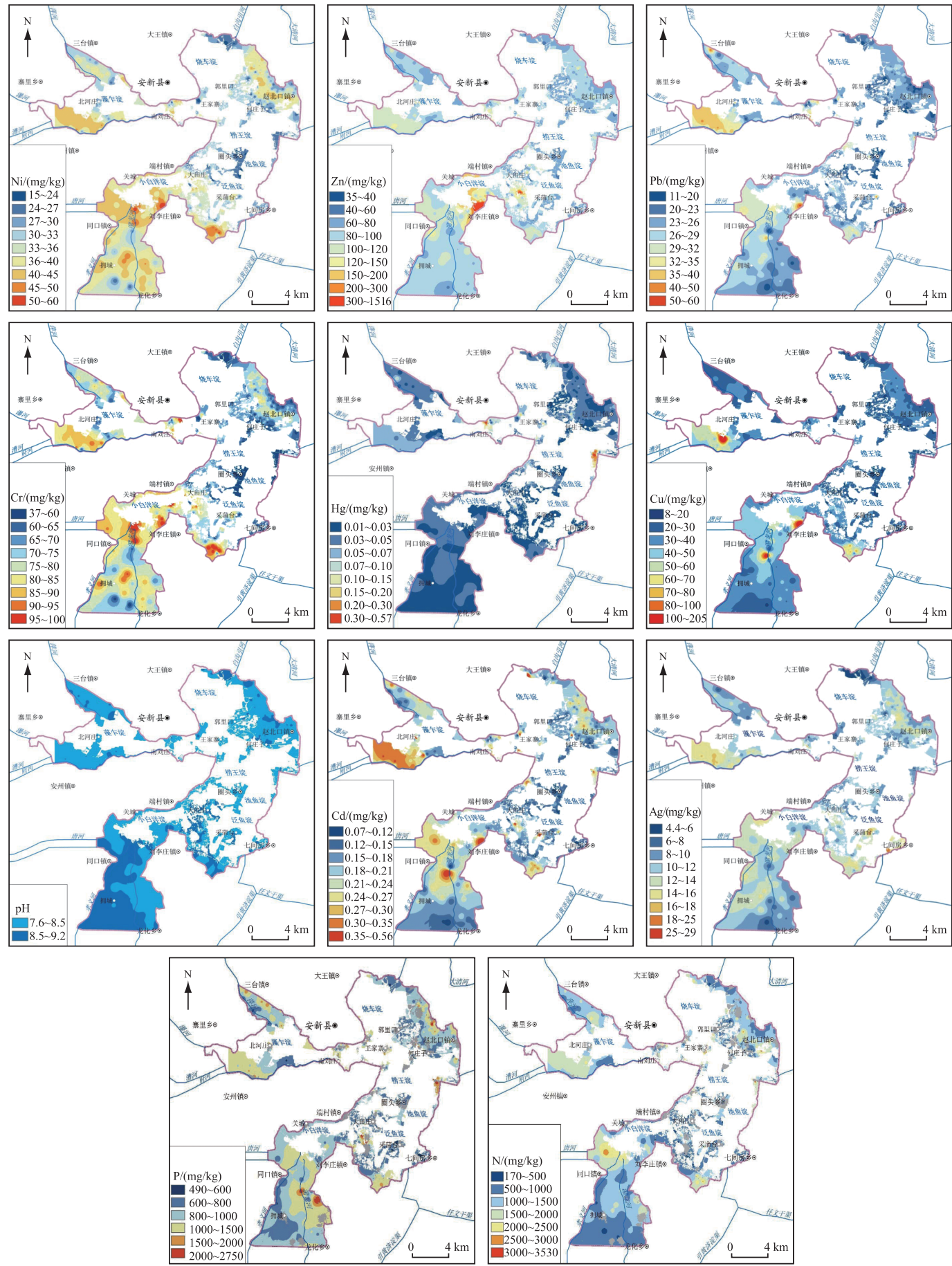

图 2 白洋淀淀区土壤主要环境元素空间分布

Fig.2 Spatial distribution of main environmental elements in soil of Lake Baiyangdian

综上, 人类活动是淀区表层土壤主要环境元素分布特征的关键影响因素. 不同土地利用类型中 $\mathrm{Hg}$ 元素无显 
著差异, 是 $\mathrm{Hg}$ 具有极强的挥发性, 是自然界唯一能 以气相形式存在的金属元素,可在大气中进行长距 离的迁移导致 ${ }^{[22-23]}$, 但仍与人类活动有一定关系 ${ }^{[24]}$. 建设用地的 $\mathrm{Hg}$ 元素含量均值最高, 是因为该区域人 类活动最为密集; 农用地次之,且旱地 $\mathrm{Hg}$ 元素含量 均值高于水田, 是因为淀区旱地为一年两熟或多数, 水田为一年一熟, 旱地人类活动较水田更密集, 而林 草荒地人类活动影响较小, 因此其含量均值也最低. 其他重金属元素在农用地表现为富集,主要由大气 干湿沉降和人类农业活动影响导致,淀区水田以水 稻和莲藕为主, 旱地以小麦、玉米和梨园为主, 大田 作物施肥主要为氮肥、复合肥和磷肥,经济作物适当 补充锌肥,波尔多液和福美胂等农药也是本区域经 济作物主要的抗菌农药,而 $\mathrm{Cd} 、 \mathrm{As} 、 \mathrm{Zn} 、 \mathrm{~Pb} 、 \mathrm{Cu}$ 重金属 表 2 不同土地利用类型环境元素方差齐性分析

Tab.2 Analysis of the variance homogeneity of environmental elements of different land types

\begin{tabular}{ccccc}
\hline 元素 & Levene 统计量 & $\mathrm{d} f 1$ & $\mathrm{~d} f 2$ & $P$ \\
\hline $\mathrm{Hg}$ & 4.870 & 3 & 416 & 0.002 \\
$\mathrm{Ni}$ & 3.730 & 3 & 416 & 0.011 \\
$\mathrm{Cu}$ & 12.481 & 3 & 416 & 0 \\
$\mathrm{Cd}$ & 0.783 & 3 & 416 & 0.504 \\
$\mathrm{Cr}$ & 1.546 & 3 & 416 & 0.202 \\
$\mathrm{As}$ & 2.941 & 3 & 416 & 0.033 \\
$\mathrm{~Pb}$ & 0.610 & 3 & 416 & 0.609 \\
$\mathrm{Zn}$ & 1.762 & 3 & 416 & 0.154 \\
$\mathrm{P}$ & 11.700 & 3 & 416 & 0 \\
$\mathrm{~N}$ & 6.983 & 3 & 416 & 0 \\
\hline
\end{tabular}
来源之一正是上述肥料和农药的施用. 此外淀区农 用地地表开阔,适合大气物质沉降地表, 加之地表土壤粗糙松软, 有利于元素物质的汇集, 这与潘粤明研究 结果一致 ${ }^{[25]}$, 即中国北方 $\mathrm{Cu} 、 \mathrm{~Pb} 、 \mathrm{Zn} 、 \mathrm{Cd} 、 \mathrm{As}$ 等重金属的大气输人量与它们在农业表层土壤中的增加量相 同. 此外重金属元素和 $\mathrm{N}$ 在水田类型富集最为突出,因为本研究区水田以黏性土 (壤土为 $22 \%$,黏土为 $78 \%$ ) 为主, 旱地 (壤土为 $66.7 \%$, 黏土为 $27 \%$ )、建设用地 (壤土为 $85 \%$, 黏土为 $7.4 \%$ ) 和林草荒地 (壤土为 $72 \%$, 黏土为 $11 \%$ ) 以壤土为主, 土壤越粘重, 越有利于元素富集, 此外据调查访问安新县农业局, 淀区氮肥 使用情况一般为水田>水浇地 >旱地,这是 $\mathrm{N}$ 元素在水田富集的重要因素. 而 $\mathrm{P}$ 元素在旱地表现为富集,一 是与 $\mathrm{P}$ 的淋失特性相关, 因为旱地对 $\mathrm{P}$ 的吸附无论在强度还是容量方面均大于同母质的水田土壤 ${ }^{[26]}$; 二是 与淀区磷肥施用有关,安新县农业局访问结果,淀区磷肥使用情况一般为旱地>水田>水浇地.

表 3 不同土地利用类型环境元素均值参数检验

Tab.3 Tests on the mean parameters of environmental elements of different land types

\begin{tabular}{cccccccccccc}
\hline & 参数检验方法 & $\mathrm{Hg}$ & $\mathrm{Ni}$ & $\mathrm{Cu}$ & $\mathrm{As}$ & $\mathrm{P}$ & $\mathrm{N}$ & $\mathrm{Cd}$ & $\mathrm{Cr}$ & $\mathrm{Pb}$ & $\mathrm{Zn}$ \\
\hline \multirow{2}{*}{$P$ 值 } & 方差分析 & 0.501 & 0 & 0 & 0.003 & 0 & 0 & - & - & - & - \\
& Welch 检验 & - & - & - & - & - & - & 0 & 0 & 0 & 0.001 \\
& Brown-Forsythe 检验 & - & - & - & - & - & - & - & - & - & 0.006 \\
\hline
\end{tabular}

表 4 不同土地利用类型元素均值差异显著性多重比较

Tab.4 Multiple comparisons of the element's significance of different land types

\begin{tabular}{ccccccccccc}
\hline 类型组合 & $\mathrm{Ni}$ & $\mathrm{Cu}$ & $\mathrm{Cd}$ & $\mathrm{Cr}$ & $\mathrm{As}$ & $\mathrm{Pb}$ & $\mathrm{Zn}$ & $\mathrm{P}$ & $\mathrm{N}$ \\
\hline 建设用地一早地 & 0 & 0.001 & 0 & 0 & 0.024 & 0 & $0.468^{*}$ & 0.003 & 0.021 \\
建设用地一水田 & 0 & 0 & 0 & 0 & 0 & 0.002 & 0.030 & $0.345^{*}$ & 0 \\
建设用地一林草荒地 & 0.040 & $0.970^{*}$ & $1.000^{*}$ & $0.120^{*}$ & $0.143^{*}$ & $0.982^{*}$ & $0.848^{*}$ & 0.006 & $0.910^{*}$ \\
早地一水田 & 0.004 & 0 & 0.067 & $0.341^{*}$ & 0.044 & $0.410^{*}$ & $0.210^{*}$ & 0.006 & 0.003 \\
早地一林草荒地 & 0 & 0.003 & 0 & 0.002 & $0.541^{*}$ & 0.025 & 0.029 & 0 & 0.032 \\
水田一林草荒地 & 0 & 0 & 0 & 0 & 0.017 & 0.009 & 0.001 & $0.362^{*}$ & 0 & 0 \\
\hline
\end{tabular}

显著性水平为 $0.05, *$ 表示无显著差异.

\section{4 白洋淀土壤环境元素物源分析}

自然界元素间多具有共生规律和伴生关系, 因此对具有相似来源的元素可采用相关分析法予以辅助确 定 ${ }^{[25]}$. 淀区土壤环境元素 Pearson 相关系数如表 5 所示. 由表可见,达到中度显著 $(r>0.5, P=0.05)$ 相关以上 


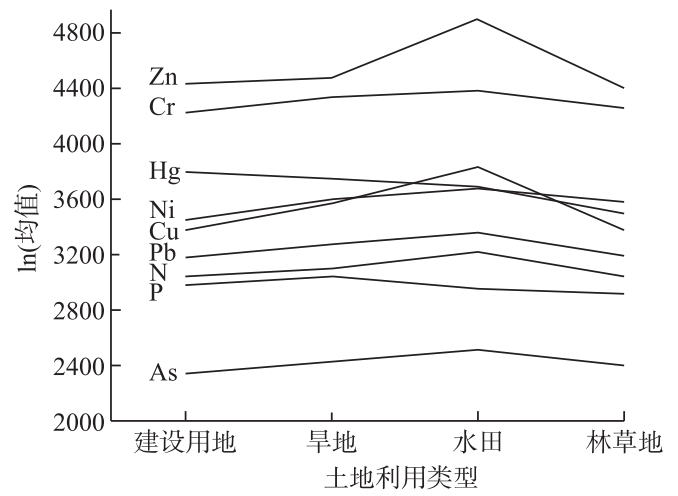

图 3 不同土地利用类型环境元素分布示意

Fig.3 Distribution of environmental elements in different land types

的元素大概分为 5 组: 分别是 $\mathrm{Cd} 、 \mathrm{Cr} 、 \mathrm{~Pb} 、 \mathrm{Cu} 、 \mathrm{Ni}$; $\mathrm{As}$ 、 $\mathrm{Cr} 、 \mathrm{Ni} ; \mathrm{N}$ 与 $\mathrm{P}$; $\mathrm{Cu}$ 与 $\mathrm{Zn}$; $\mathrm{N}$ 与 $\mathrm{Cd} 、 \mathrm{~Pb}$. 说明上述 5 组元 素间存在一定程度的共源性或相似的富集途径.

根据郭海泉等对河北平原土壤重金属元素富集因 子分析 ${ }^{[27-28]}$ 得知, $\mathrm{Cr} 、 \mathrm{~Pb} 、 \mathrm{Cu} 、 \mathrm{Ni}$ 具有相近的污染富集 特征, 这和第一组高度契合. 据中国科学院大气物理 研究所潘月鹏等 ${ }^{[29]}$ 对中国北方区域冬季大气干沉降 颗粒分析得知, 保定地区大气颗粒中重金属 $\mathrm{Pb} 、 \mathrm{Cu}$ 、 $\mathrm{Ni} 、 \mathrm{Cr} 、 \mathrm{Zn}$ 显著高于京津冀的均值, 说明第一组主要共 源之一是外来的大气沉降.

第二组 $\mathrm{As}$ 和 $\mathrm{Cr} 、 \mathrm{Ni}$ 表现出中度显著相关性, Cr、 $\mathrm{Ni}$ 高度相关, 由第一组分析可知是大气沉降是 $\mathrm{Cr} 、 \mathrm{Ni}$ 的主要来源, 前述分析淀区 As 元素主要来源有 2 个一一农业和大气输人, 本组 $\mathrm{As}$ 表现出与 $\mathrm{Cr} 、 \mathrm{Ni}$ 中度 显著相关, 说明 As 来自于大气沉降的比例要大于农业 肥料农药的施用.

第三组 $\mathrm{N}$ 与 $\mathrm{P}$, 既是农业肥料 (化肥和农家肥) 的主要元素, 也是畜牧养殖排放的主要成分, 淀区除了农 业、村镇就是水面, 没有规模化的畜牧养殖场地, 因此两者显著相关主要是农业施肥造成的, 因此肥料是两 者的共源因素.

第四组 $\mathrm{Cu}$ 与 $\mathrm{Zn}, \mathrm{Cu}$ 也是其他重金属的共源元素, $\mathrm{Zn}$ 虽然和其他重金属相关性达不到中等, 但是也和 $\mathrm{Cd} 、 \mathrm{~Pb} 、 \mathrm{Ni}$ 达到了低度显著相关, 说明 $\mathrm{Zn}$ 和第一组也存在一定的共源性, 但是还有其他方面影响导致 $\mathrm{Zn}$ 和 $\mathrm{Cu}$ 相关性进一步加强, 据张秀芝等的研究 ${ }^{[12]}$, 白洋淀区中西部 (李庄镇周边) 分布有数家简易炼铜厂、炼锌 厂及小一中型的电镀厂 ( 以镀锌、铜为主), 这也与 $\mathrm{Zn}$ 和 $\mathrm{Cu}$ 高值区的空间分布相一致, 说明小冶炼使得 $\mathrm{Cu}$ 、 $\mathrm{Zn}$ 的相关关系增强.

第五组 $\mathrm{N}$ 与 $\mathrm{Cd} 、 \mathrm{~Pb}, \mathrm{~N}$ 元素除了地质原生背景外, 最重要一部分来自农业氮肥. 而氮肥含有较多的杂 质, 尤其对于硫酸铵氮肥来说, 其中重金属含量超过尿素的几十倍 ${ }^{[30]}$, 因此这一组共源性是氮肥的施用.

表 5 淀区表层土壤主要环境元素 Pearson 相关系数

Tab.5 Pearson correlation coefficients of main environmental elements in the surface soil of Lake Baiyangdian lands

\begin{tabular}{|c|c|c|c|c|c|c|c|c|c|c|c|}
\hline & $\mathrm{Hg}$ & As & $\mathrm{Cr}$ & $\mathrm{Ni}$ & $\mathrm{Cu}$ & $\mathrm{Zn}$ & $\mathrm{Cd}$ & $\mathrm{Pb}$ & $\mathrm{N}$ & $\mathrm{P}$ & $\mathrm{pH}$ \\
\hline $\mathrm{Hg}$ & 1 & & & & & & & & & & \\
\hline As & 0.015 & 1 & & & & & & & & & \\
\hline $\mathrm{Cr}$ & $0.100^{*}$ & $0.600^{* * *}$ & 1 & & & & & & & & \\
\hline $\mathrm{Ni}$ & 0.062 & $0.660^{* *}$ & $0.934^{* *}$ & 1 & & & & & & & \\
\hline $\mathrm{Cu}$ & $0.128^{* *}$ & $0.400^{\text {*** }}$ & $0.602^{* *}$ & $0.642^{* *}$ & 1 & & & & & & \\
\hline $\mathrm{Zn}$ & 0.074 & $0.121^{*}$ & $0.290^{\text {** }}$ & $0.350^{* * *}$ & $0.585^{* *}$ & 1 & & & & & \\
\hline $\mathrm{Cd}$ & $0.295^{* * *}$ & $0.319^{\text {** }}$ & $0.504^{* *}$ & $0.523^{* *}$ & $0.603^{* *}$ & $0.424^{* *}$ & 1 & & & & \\
\hline $\mathrm{Pb}$ & $0.267^{* *}$ & $0.449^{* * *}$ & $0.659^{* *}$ & $0.658^{* *}$ & $0.636^{* *}$ & $0.419^{* *}$ & $0.767^{* *}$ & 1 & & & \\
\hline $\mathrm{N}$ & $0.340^{* * *}$ & $0.202^{\text {*** }}$ & $0.417^{* *}$ & $0.440^{* *}$ & $0.371^{* * *}$ & $0.180^{* *}$ & $0.723^{* *}$ & $0.597^{* *}$ & 1 & & \\
\hline $\mathrm{P}$ & $0.390^{* *}$ & 0.003 & $0.122 *$ & 0.073 & $0.193^{* *}$ & $0.115^{*}$ & $0.497^{* *}$ & $0.325^{* *}$ & $0.503^{* *}$ & 1 & \\
\hline $\mathrm{pH}$ & $-0.280^{* *}$ & -0.046 & $-0.108^{*}$ & $-0.132^{* *}$ & $-0.126^{* *}$ & $-0.134^{* *}$ & $-0.338^{* *}$ & $-0.282^{* *}$ & $-0.481^{\text {*** }}$ & $-0.243^{* *}$ & 1 \\
\hline
\end{tabular}

*表示 0.05 显著水平, $* *$ 表示 0.01 显著水平.

为进一步探讨淀区表层土壤环境元素的来源和影响因素, 对上述环境元素进行因子分析. 本文环境元 素数据 Bartlett 球度检验结果伴随概率值 $\operatorname{sig}=0<0.05$, 检验显著; KMO $=0.812$, 适合进行因子分析. 因子分析 结果得到 3 个特征值大于 1 的主因子, 累计方差解释程度达到了 $75.6 \%$. 为了使公共因子的典型性更加突 
出, 因子解的意义更容易解释, 对主成分矩阵进行正 交旋转,结果如表 6 所示, 除了 $\mathrm{Pb} 、 \mathrm{Cd}$ 横跨 3 个因子 出现三载荷, $\mathrm{Cu}$ 横跨 2 个因子出现两载荷外,其他元 素均为单载荷, 因此无须进行斜交旋转.

第一主成分因子的方差贡献率为 $31.9 \%$, 因子载 荷大于 0.4 的元素有 $\mathrm{Ni} 、 \mathrm{Cr} 、 \mathrm{As} 、 \mathrm{~Pb} 、 \mathrm{Cu}$ 和 $\mathrm{Cd}$,这与相 关分析中第一组基本类似,但是多了 As 元素, 这与 第二组也有了交叉,从表 5 可以看出, $\mathrm{As}$ 除了与 $\mathrm{Cr}$ 、 $\mathrm{Ni}$ 中度显著相关外, 与 $\mathrm{Pb} 、 \mathrm{Cu} 、 \mathrm{Cd}$ 也达到了低度显 著相关,而上述组分主要是燃煤烟气中的主要成分. 这说明因子 1 元素主要除了原生地质背景外, 主要 由燃煤形成烟气, 在大气携带下产生的干湿沉降造 成的, 因此命名为大气沉降型.

第二主因子的方差贡献率为 $24.2 \%$, 因子载荷大 于 0.4 的元素有 $\mathrm{P} 、 \mathrm{~N} 、 \mathrm{Hg} 、 \mathrm{Cd} 、 \mathrm{~Pb}$. 因子 2 元素是相关 分析中第三组和第五组的组合,该主成分元素的富 集除元素背景外, 主要来源于农业肥料. $\mathrm{N} 、 \mathrm{P}$ 是氮 肥、磷肥中的主要元素, 而 $\mathrm{Hg} 、 \mathrm{Cd} 、 \mathrm{~Pb}$ 又是肥料中常 见的伴生元素. 我国肥料种类繁多,除了水溶性化肥 外, 还有有机肥、复合肥等, 其中 $\mathrm{As} 、 \mathrm{~Pb} 、 \mathrm{Cd} 、 \mathrm{Hg}$ 是有 机肥料中最容易出现超标的重金属元素 ${ }^{[31]}$. 综上, 因 子 2 命名为农业输人型.

第三主因子的方差贡献率为 $19.5 \%$, 因子载荷大于 0.4 的元素有 $\mathrm{Cu} 、 \mathrm{Zn} 、 \mathrm{Cd}$ 和 $\mathrm{Pb}$. 因子 3 是相关分析中 第四组共源元素的反映, 其中次要载荷因子 $\mathrm{Cd} 、 \mathrm{~Pb}$ 既有大气沉降的因素也有农业输人的因素, 但主要载荷 因子 $\mathrm{Cu} 、 \mathrm{Zn}$ 却是前述分析白洋淀周边众多的铜、锌小冶炼作坊无序排放引起的. 因此因子 3 命名为工业叠 加型.

\section{3 结论}

1) 白洋淀淀区内土壤主要环境元素含量,除元素 P 外, 其余元素的淀区背景值均高出区域背景值, 呈富 集趋势.

2) 受大气沉降和农业活动影响,大部分元素趋向于农用地类型富集,除 $\mathrm{P}$ 元素外,在水田的富集最为突 出; 受周边小冶炼工业活动影响,在淀区局部(李庄镇区域) 出现重金属富集的现象. $\mathrm{Hg}$ 元素在人类活动最 为密集的村镇等建设用地最为富集.

3 ) 淀区内土壤主要环境元素的来源分为 3 种类型: 大气沉降型, 代表性元素为 $\mathrm{Ni} 、 \mathrm{Cr} 、 \mathrm{As} 、 \mathrm{~Pb} 、 \mathrm{Cu}$ 和 $\mathrm{Cd}$, 主要来源于淀区燃煤烟气的大气沉降; 农业输人型, 代表性元素为 $\mathrm{P} 、 \mathrm{~N} 、 \mathrm{Hg} 、 \mathrm{Cd} 、 \mathrm{~Pb}$ 主要来源于农业施肥和 人类生活; 工业叠加型, 代表性元素为 $\mathrm{Zn} 、 \mathrm{Cu} 、 \mathrm{Cd} 、 \mathrm{~Pb}$, 主要来源于淀区大气的沉降, 周边小冶炼作坊的无序 排放对其分布产生叠加影响.

致谢:感谢王旭清、尹德超提供的图件.

\section{4 参考文献}

[ 1 ] Liu ZW , Su YL, Yang L. Limnology is a multidisciplinary and integrative science for studying inland waters: With special reference to the challenges and opportunities for the development of limnology in China. J Lake Sci, 2020, 32(5) : 12441253. DOI: $10.18307 / 2020.0502$. [刘正文, 苏雅玲, 杨柳. 湖沼学是研究内陆水体的多学科整合科学一一兼论我 国湖沼学发展面临的挑战与机遇. 湖泊科学, 2020,32(5): 1244-1253.]

[ 2 ] Yang XD, Dong XH, Chen X et al. Past environmental changes and management suggestions for lakes in the Yangtze River 
economic belt. Bulletin of the Chinese Academy of Sciences, 2020, 35(8): 977-987. [羊向东, 董旭辉, 陈旭等. 长江经 济带湖泊环境演变与保护、治理建议. 中国科学院院刊, 2020, 35(8): 977-987.]

[ 3 ] Hebei Provincial Committee of Local Chronicles ed. Annals of Hebei Province: Volume 3 physical geography. Shijiazhuang: Science and Technology Press, 1993: 218-219. [河北省地方志纂委员会. 河北省志:第 3 卷自然地理志. 石 家庄: 科学技术出版社, 1993: 218-219.]

[ 4 ] Yi YJ, Lin CQ, Tang CH. Hydrology, environment and ecological evolution of Lake Baiyangdian since 1960s. J Lake Sci, 2020, 32(5) : 1333-1347. DOI: 10.18307/2020.0500. [易雨君, 林楚翘, 唐彩红. 1960s 以来白洋淀水文、环境、生 态演变趋势. 湖泊科学, 2020, 32(5): 1333-1347.]

[ 5 ] Zhang M, Gong ZN, Zhao WJ et al. Landscape pattern change and the driving forces in Baiyangdian wetland from 1984 to 2014. Acta Ecologica Sinica, 2016, 36(15) : 4780-4791. DOI: 10.5846/stxb201501140110. [张敏, 宫兆宁, 赵文吉 等. 近 30 年来白洋淀湿地景观格局变化及其驱动机制. 生态学报, 2016, 36(15) : 4780-4791.]

[ 6 ] Zhao X, Cui BS, Yang ZF. A study of the lowest ecological water level of Baiyangdian Lake. Acta Ecologica Sinica, 2005, 25(5) : 1033-1040. [ 赵翔, 崔保山, 杨志峰. 白洋淀最低生态水位研究. 生态学报, 2005, 25 (5) : 1033-1040.]

[ 7 ] Zhu JF, Zhou Y, Wang SX et al. Ecological function evaluation and regionalization in Baiyangdian Wetland. Acta Ecologica Sinica, 2020, 40(2). DOI: 10.5846/stxb201901280209.

[ 8 ] Wang WJ, YujunYi, Yang YF et al. Impact of anthropogenic activities on the sediment microbial communities of Baiyangdian shallow lake. International Journal of Sediment Research, 2020, 35(2): 180-192. DOI: 10. 1016/j. ijsrc. 2019. 10.006 .

[ 9 ] Wang HN, Lv X, Zhang MY. Sensitivity and attribution analysis based on the Budyko hypothesis for streamflow change in the Baiyangdian catchment, China. Ecological Indicators, 2021, 121: 107221. DOI: 10.1016/j.ecolind.2020.107221.

[10] Hu SS, Zheng HX, Liu CM et al. Assessing the impacts of climate variability and human activities on streamflow in the water source area of Baiyangdian Lake. Acta Geographica Sinica, 2012, 67(1):62-70. [ 胡珊珊, 郑红星, 刘昌明等. 气候 变化和人类活动对白洋淀上游水源区径流的影响. 地理学报, 2012, 67(1):62-70.]

[11] Wang JZ, Liu Z, Wei H et al. Spatial characteristics, risk assessment, and source analysis of elements in surface sediments from the Baiyangdian Lake. Environmental Science, 2020, 41(1) : 224-231. DOI: 10.13227/j. hjkx. 201907005. [汪敬忠, 刘卓, 魏浩等. 白洋淀表层沉积物元素的空间特征、风险评价及来源分析. 环境科学, 2020, 41 (1) : 224-231. ]

[12] Zhang XZ, Guo HQ, Li HL et al. Distinguishing origins of elements in environmental geochemistry of Baiyangdian billabong of Hebei Province, North China. Earth Science Frontiers, 2008, 15(5): 90-96. [张秀芝, 郭海全, 李宏亮等. 河北 省白洋淀洼地环境地球化学物源判断. 地学前缘, 2008, 15(5): 90-96.]

[13] Government of the People's Republic of China, Hebei Province ed. Overall plan for Xiongan new district, Hebei Province (2018-2035).2018.[河北省人民政府. 河北雄安新区总体规划(2018一2035 年). 2018.]

[14] Liu X, Shi B, Meng J et al. Spatio-temporal variations in the characteristics of water eutrophication and sediment pollution in Baiyangdian Lake. Environmental Science, 2020, 41(5): 2127-2136. DOI: 10.13227/j. hjkx.201909263. [刘崟金, 史 斌, 孟晶等. 白洋淀水体富营养化和沉积物污染时空变化特征. 环境科学, 2020, 41(5): 2127-2136.]

[15] Gao QS, Tian ZQ, Jiao LX et al. Pollution characteristics and ecological risk assessment of heavy metals in Baiyangdian Lake. Journal of Environmental Engineering Technology, 2019, 9(1):66-75. [高秋生, 田自强, 焦立新等. 白洋淀重 金属污染特征与生态风险评价. 环境工程技术学报, 2019, 9(1): 66-75.]

[16] He NH, Zhu XQ. Discussion of the formation cause of Lake Baiyangdian. Geography and Territorial Research, 1993, (1) : 54-55. [何乃华, 朱宣清. 白洋淀形成原因的探讨. 地理学与国土研究, 1993，(1) : 54-55.]

[17] Wang YS, Yin DC, Wang XQ et al. Annual Report on the ecological geological survey of the Baiyang Lake region. Baoding: hydrogeological and Environmental Geological Survey Center, China Geological Survey, 2020. [王雨山, 尹德超, 王 旭清等. 白洋淀地区生态地质调查年度报告. 保定: 中国地质调查局水文地质环境地质调查中心, 2020.]

[18] Cao F, Li RM, Wang Y et al. Soil geochemical baseline and environmental background values in northern Haihe plain, China. Geological Bulletin of China, 2010, 29(8): 1215-1219. [ 曹峰, 李瑞敏, 王轶等. 海河平原北部地区土壤地球 化学基准值与环境背景值. 地质通报, 2010, 29(8): 1215-1219.]

[19] Wang J, Niu WQ, Zhang WQ et al. Spatial variability of soil nutrients in topsoil of cultivated land. Transactions of the Chinese Society of Agricultural Engineering, 2020, 36(15) : 37-46. [王婕, 牛文全, 张文倩等. 农田表层土壤养分空间变 
异特性研究. 农业工程学报, 2020, 36(15): 37-46.]

[20] Jia JP, He XQ, Jin YJ eds. Statistics(The seventh edition). Beijing: China Renmin University Press, 2018. [贾俊平, 何 晓群, 金勇进. 统计学: 第 7 版. 北京: 中国人民大学出版社, 2018.]

[21] Li ZH, Luo P eds. SPSS course in common statistical analysis (SPSS 22.0 in English and Chinese) (4th edition). Beijing: Publishing House of Electronics Industry, 2015. [李志辉, 罗平. SPSS 常用统计分析教程( SPSS 22.0 中英文版) (第 4 版). 北京: 电子工业出版社, 2015.]

[22] Liu H, Lu AG. Progress in research on wet deposition of mercury. Bulletin of Science and Technology, 2018, 34(11): 110. [ 刘晖, 卢爱刚. 大气湿沉降录的研究进展. 科技通报, 2018, 34(11): 1-10.]

[23] Xie SQ. Transport and transformation of different forms of mercury in the atmosphere. China Chemical Trade, 2017, 9 (14) : 204-207. [谢世强. 大气中不同形态永的迁移转化. 中国化工贸易, 2017, 9(14) : 204-207.]

[24] Zhang HX, Huo SL, Yeager KM et al. A historical sedimentary record of mercury in a shallow eutrophic lake: Impacts of human activities and climate change. Engineering, 2019, 5(2) : 296-304. DOI: 10.1016/j.eng.2018.11.022.

[25] Pan YP, Wang YS. Atmospheric wet and dry deposition of trace elements at 10 sites in Northern China. Atmospheric Chemistry and Physics, 2015, 15(2): 951-972. DOI: 10.5194/acp-15-951-2015.

[26] Qiu YQ, Peng PQ, Hou HB et al. Environmental Risk and control of phosphorus in upland and paddy soils. The twelve th National Congress of the Soil Society of China and the 9th Cross Strait soil and fertilizer academic exchange seminar, 2012 [邱亚群, 彭佩钦, 侯红波等. 旱地与水田土壤磷素的环境风险和控制. 中国土壤学会第十二届全国会员代表大 会暨第九届海峡两岸土壤肥料学术交流研讨会, 2012.]

[27] Li PY, Qian H, Wu JH et al. Major ion chemistry of shallow groundwater in the Dongsheng coalfield, Ordos Basin, China. Mine Water and the Environment, 2013, 32(3) : 195-206. DOI: 10.1007/s10230-013-0234-8.

[28] Guo HQ, Hao JJ, Li TG et al. Application of an enrichment factor in determining anthropogenic pollution of heavy metal in topsoil in Hebei plain. Ecology and Environmental Sciences, 2010, 19(4) : 786-791. [ 郭海全, 郝俊杰, 李天刚等. 河北 平原土壤重金属人为污染的富集因子分析. 生态环境学报, 2010, 19(4): 786-791.]

[29] Pan YP, Wang YS, Yang YJ et al. Determination of trace metals in atmospheric dry deposition with a heavy matrix of PUF by inductively coupled plasma mass spectroscopy after microwave digestion. Environmental Science, 2010, 31(3) : 553559. DOI: 10.13227/j.hjkx.2010.03.012. [潘月鹏, 王跃思, 杨勇杰等. 区域大气颗粒物干沉降采集及金属元素分析 方法. 环境科学, 2010, 31(3) : 553-559.]

[30 ] Chen LH, Ni WZ, Li XL et al. Investigation of heavy metal concentrations in commercial fertilizers commonly-used. Journal of Zhejiang Institute of Science and Technology, 2009, 26(2): 223-227. [ 陈林华, 倪吾钟, 李雪莲等. 常用肥料重 金属含量的调查分析. 浙江理工大学学报, 2009, 26(2): 223-227.]

[31] Jiang N, Ping LW, Ji XH et al. Content analysis and pollution risk assessment of heavy metal in common fertilizers in typical north vegetable fields. Journal of Agro-Environment Science, 2020, 39(3) : 521-529. DOI: 10.11654/jaes.2019-1154. [江南, 平令文, 季晓慧等. 典型北方菜田常用肥料中重金属含量分析及污染风险评价. 农业环境科学学报, $2020,39(3)$ : 521-529.] 